\title{
Gynecological cancer among adolescents and young adults (AYA)
}

\author{
Silvia Triarico ${ }^{1}$, Michele Antonio Capozza ${ }^{2}$, Stefano Mastrangelo ${ }^{1,3}$, Giorgio Attinà ${ }^{1}$, Palma Maurizi ${ }^{1,3}$, \\ Antonio Ruggiero ${ }^{1,3}$
}

${ }^{1}$ Unità di Oncologia Pediatrica, Fondazione Policlinico Universitario A. Gemelli IRCCS, Università Cattolica Sacro Cuore, Rome, Italy; ${ }^{2}$ Scuola di Specializzazione in Pediatria, Università Cattolica del Sacro Cuore, Rome, Italy; ${ }^{3}$ Istituto di Pediatria, Università Cattolica del Sacro Cuore, Rome, Italy

Contributions: (I) Conception and design: S Triarico, P Maurizi, A Ruggiero; (II) Administrative support: G Attinà; (III) Provision of study materials or patients: MA Capozza; (IV) Collection and assembly of data: S Mastrangelo; (V) Data analysis and interpretation: S Triarico; (VI) Manuscript writing: All authors; (VII) Final approval of manuscript: All authors.

Correspondence to: Silvia Triarico, MD. Unità di Oncologia Pediatrica, Fondazione Policlinico Universitario A. Gemelli IRCCS, Università Cattolica Sacro Cuore, Largo A. Gemelli, 8, 00168 Rome, Italy. Email: silviatriarico@libero.it.

\begin{abstract}
Adolescents and young adults (AYA) patients with cancer show specific biological, sociodemographic and behavioral features, with lower survival rates than younger group. Gynecologic malignancies that occur among AYA requires a multidisciplinary management and a tailored model of care, in order to enhance the early diagnosis, the adherence to the treatment, the enrollment in clinical trials, the rate of survival and the quality of life (QoL). In this article, we review the main gynecological tumors that may occur in AYA, with a focus on the clinical signs at the diagnosis and the modality of treatment. In addition, we proposed a model of multidisciplinary and personalized care for AYA with gynecological tumors, which can help the clinicians to manage the specific gynecologic concerns, such as ovarian failure, contraception, fertility, late psychosocial effects.
\end{abstract}

Keywords: Adolescents and young adults (AYA); gynecologic tumors; personalized care; gynecological concerns; oncofertility strategies

Submitted Nov 01, 2019. Accepted for publication Jan 03, 2020.

doi: $10.21037 /$ atm.2020.02.41

View this article at: http://dx.doi.org/10.21037/atm.2020.02.41

\section{Introduction}

Despite the lack of universal consensus for defining adolescents and young adults (AYA), the National Cancer Institute (NCI) and the European Network for Cancer Research in Children and Adolescents (ENCCA) agree in defining adolescents and AYA with the age range 1539 years (1).

Cancer is an important problem among AYA, with a global annual incidence estimated at one million and a significant mortality (2). Over the last 30 years, AYA oncology patients have not shared the improvement of cure rate obtained for the children with cancer (3) and cancer still remains the leading cause of disease-death among people aged 15-24 years and the second among 25-39 years old (4). The reason of the distinct gap between survival outcomes of AYA and younger age group seems to be multifactorial, due to the specific requirements of this group of age and their decreased enrollment in therapeutic clinical trials (5). Moreover, AYA with cancer need tailored approaches and management according to their unique socio-demographic issues, behavioral patterns, the different tumor type, the distinctive physiological state (6-8).

The need for a personalized program of care should be considered from initial diagnosis to treatment and follow-up for female AYA affected by gynecological cancer. Gynecological malignancies are rare within the pediatric and adolescent populations and they may originate mainly from the ovary, but also from uterus, cervix, vagina and vulva (9). Clinicians must be aware of the most current recommendations and clinical trials for chemotherapy, radiation and surgical therapy of gynecologic malignancies 
in AYA. Besides, they should be careful of the specific biological, sociodemographic and behavioral features of these patients. In addition, they have to consider and manage the possible impact of the treatment on patients' physical and social development, body image, ovarian function and fertility (10-12).

In this article, we reviewed the main malignant gynecological tumors that may occur in AYA, with a focus on the clinical signs at the diagnosis and the modality of treatment. In addition, we proposed a model of multidisciplinary and personalized care for AYA with gynecological tumors, including the management of their specific gynecological concerns, in order to enhance early diagnosis, adherence to the treatment, enrollment in clinical trials, the rate of survival and QoL.

\section{Gynecological tumors in AYA}

Genital tract tumors in girls can cause genital bleedings or smelly secretion, abdominal pain, but also premature sexual maturation (13).

The most common presenting symptom of ovarian tumors is abdominal pain (57\%), followed by the presence of a palpable abdominal or pelvic mass (46\%). Furthermore, they may present gastrointestinal symptoms, such as poor appetite, weight loss, constipation, nausea or vomiting (14).

Abdominal pain is usually the first symptom of Germ Cell Tumors and Sex Cord-Stromal Tumors, because of the possibility of torsion, hemorrhage, or rupture (15).

Hormone-producing ovarian tumors can cause endocrine abnormalities, such as precocious puberty (with breast enlargement, abnormal vaginal bleeding, pubic and axillary hair) in the premenarcheal girls, menstrual irregularity (hypermenorrhea or amenorrhea) in the adolescents (16).

Sex Cord-Stromal Tumors and gonadoblastomas usually secrete estrogen and consequently they are associated with precocious puberty and menstrual irregularity $(17,18)$.

Both prepubertal girls and female adolescents with a malignant germ cell tumor (GCT) may show signs of virilization or masculinization (acne, deepening of the voice, hirsutism, clitoral enlargement) (19).

Sertoli-Leydig cell tumor can often produce virilization as a result of androgen secretion (16).

\section{Vulva tumors}

Vulva tumors are infrequent in children and adolescents. The relative bigger incidence of vulvar neoplasms in adult women compared to pediatric age is likely related to the influence of environmental factors, including the exposure to sexually transmitted diseases, such as human papillomavirus (HPV) $(20,21)$.

In children and adolescents, malignant tumors arising from vulva are very rare, still sarcoma botryoides (rhabdomyosarcoma) and endodermal sinus tumors are described in the literature $(22,23)$.

\section{Vaginal and cervical tumors}

Malignant neoplasms of the vagina and cervix in the newborns, children and adolescents are sporadic. In this age group, the most common neoplasm of the lower genital tract is the sarcoma botryoides, followed by endodermal sinus tumors. Endodermal sinus tumors or yolk sac tumors are most commonly seen in the very young child below the age of 3 years (24).

The clear cell adenocarcinoma (CCA) is often associated with a history of antenatal exposure to diethylstilbestrol (DES) (25).

Sarcoma botryoides is a rare embryonal variant of rhabdomyosarcoma, usually found in the vagina of infants and early childhood (especially in children less than two years of age). The onset of sarcoma botryoides from the uterine cervix is very rare, with a peak incidence in the second decade of life. These lesions are usually clinically visible with a nodular and grape-like mass which protrudes from the vagina; occasionally the only symptom may be an unexplained vaginal bleeding or the presence of an abdominopelvic mass $(24,26)$. Vulvar and vaginal sites are associated with favorable prognosis in young patients, but the most important prognostic is the extent of the disease $(27,28)$.

Complete surgical resection is possible only for small polypoid mass, thus they are usually curable with a combination of chemotherapy based on vincristine, actinomycin-D and cyclophosphamide (VAC) and the use of radiotherapy if applicable (29).

Vaginal Yolk Sac Tumors show histologic features similar to the tumors of ovarian origin. Macroscopically, they are polypoid and soft vaginal masses. Alpha-fetoprotein is generally considerably raised (30). Vaginal Yolk Sac Tumors is always treated primarily with 4 cycles of cisplatin, bleomycin, etoposide (PEB) or carboplatin, etoposide, bleomycin (JEB) or cisplatin, vinblastine, bleomycin (PVB) chemotherapy. Resection or biopsy is necessary to avoid additional primary chemotherapy or to identify patients who need different treatment. Furthermore, Taxol-salvage chemotherapy 
regimens, adjuvant modern radiotherapy and fertility-saving curative surgery should be considered $(31,32)$.

In CCA radical surgery crucial and may be associated with adjuvant radiotherapy if necessary (33). For locally advanced cervical carcinoma neoadjuvant chemotherapy with carboplatin and paclitaxel, followed by radical hysterectomy and adjuvant radiation is a highly active treatment with acceptable toxicity (34).

\section{Uterine tumors}

Uterine tumors are rare and more likely malignant in this age group. Endometrial cancer usually occurs in the $15 \%$ of cases in premenopausal women and just over $1 \%$ of patients are diagnosed before 40 years of age (35). Only a few cases of endometrial cancer have been reported in adolescents (36).

Uterine sarcomas represent about 3-9\% of malignant uterine tumors. Traditionally, the main histological categories of uterine sarcoma are leiomyosarcoma (about 40\%), carcinosarcoma (40\%) and endometrial stromal sarcoma (15\%). The remaining $5 \%$ of cases consist of a heterogeneous group of vascular and lymphatic sarcomas (37).

Uterine leiomyosarcoma (LMS) may occur in younger women and premenopausal patients, still uterine LMS is very rare during childhood and adolescence (38).

\section{Ovarian tumors}

Benign and malignant ovarian tumors are rare in the pediatric population, with an incidence which increases with age (39-41).

Juvenile Granulosa and Theca Cell Tumor are stromal ovarian carcinomas very rare in children. Surgery is necessary for histological diagnosis, staging, and debulking, but an excellent prognosis is related to early stage disease (42). Chemotherapy is indicated for stage IC or higher by FIGO (International Federation of Gynecology and Obstetrics) and it is based on cisplatin associated to ifosfamide and etoposide (PEI) or to etoposide and bleomycin (PEB) $(43,44)$.

Juvenile Granulosa Cell Tumor (JGCT) accounts about the $70 \%$ of all ovarian sex cord-stromal tumors in patients younger than 20 years (17). Approximately $80 \%$ of prepubertal girls with JGCT present isosexual precocious puberty related to estrogen secretion. Rarely, the tumor produces androgen and can cause virilizing features (45). In children, JGCT is more frequently associated with acute complications, such as torsion and rupture (46). Inhibin is a useful serum tumor marker for diagnosis and follow-up. Up to $90 \%$ of these tumors are diagnosed as low-stage disease confined to the ovary and they are usually curable only with conservative surgery. However, patients with advanced disease or tumors with high mitotic activity have a poorer prognosis and they should be treated with chemotherapy (47).

Sertoli-Leydig cell tumor is a rare stromal tumor that accounts for less than $0.5 \%$ of all malignant ovarian neoplasms in children and it is the most common androgen-producing ovarian tumor (48). Histologically, it may be classified in well-differentiated, intermediately differentiated, poorly differentiated, and retiform subtypes. Except for the well-differentiated subtype, the others may contain heterologous elements, with hepatic differentiation which is responsible for elevated serum AFP levels. Most of these tumors are diagnosed at an early-stage with usually good prognosis (49).

GTCs can be located in the ovary and are usually divide into two groups: seminomas (including dysgerminoma) and non-seminomas (including yolk sac tumor, mature and immature teratoma, embryonal carcinoma, choriocarcinoma) (50,51).

Dysgerminoma is the most frequent ovarian malignant GCT observed during the adolescence. It originates from undifferentiated germ cells and it is bilateral in $10 \%$ of cases. It is associated with gonadal dysgenesis and also with chromosomal abnormalities (such as Turner syndrome). $\mathrm{LDH}$ is a useful tumor marker for diagnosis and postoperative follow-up. Serum b-hCG levels are elevated in the $5 \%$ of cases when differentiated syncytiotrophoblastic cells are present. It is highly radiosensitive, but in the early-stage disease surgery alone is curative, with excellent prognosis (52).

Yolk sac tumor is the most common malignant entity in young population and it is usually aggressive, with growth and extensive spread to the abdominopelvic cavity. Hematogenous or peritoneal metastasis and lymphatic spread are usually observed. Alpha-fetoprotein produced by the neoplasm can be used as a tumor marker at initial diagnosis and postoperative follow-up. The prognosis depends on the disease stage. Conservative surgery and chemotherapy can be used in a lot of cases (53).

Mature Teratoma (or Dermoid cyst) is the most common benign ovarian tumor found in adolescents, with an incidence of $10-25 \%$, bilateral in the $10 \%$ of cases. The decision of surgical excision should be based on the age of the patient, future fertility and cyst size (54).

Immature teratoma frequently occurs between the first 


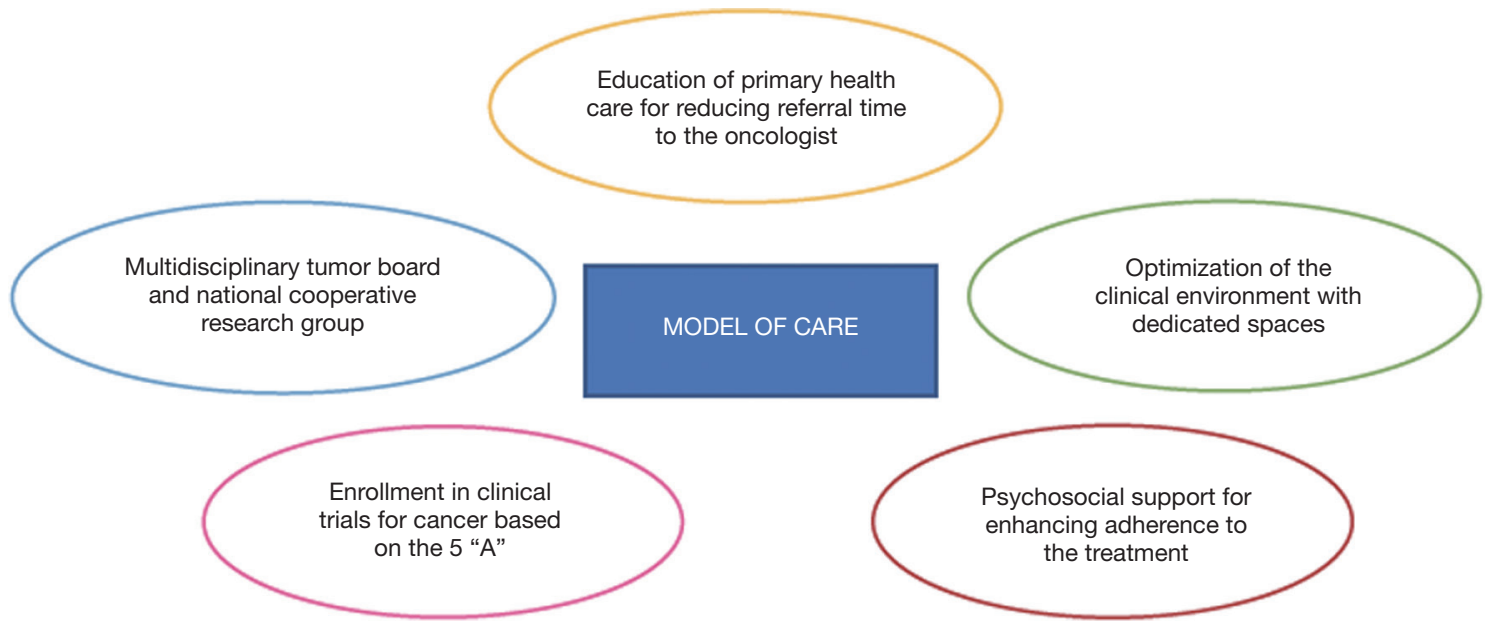

Figure 1 A personalized and multidisciplinary model of care for adolescents and AYA with gynecological tumors. AYA, adolescents and young adults.

and the second decade of life and represents $10-20 \%$ of all ovarian malignancies in patients younger than 20 years (55). It shows more aggressive behavior and worse prognosis than mature teratoma. Elevated serum AFP levels have been reported in $33-65 \%$ of patients. The current treatment of choice for immature teratoma is the surgery alone, with unilateral salpingo-oophorectomy and staging procedure (56).

Embryonal carcinoma is a rare and highly malignant tumor that accounts for approximately $3 \%$ of malignant GCTs. Isosexual precocity or menstrual irregularity, related to b-hCG secretion, occurs in up to $60 \%$ of cases. The tumor can produce AFP and b-hCG, which may help in diagnosis and treatment monitoring. Standard staging laparotomy with unilateral salpingo-oophorectomy should be performed, followed by postoperative chemotherapy (57).

Except for localized dysgerminomas and immature teratomas, in the other cases BEP chemotherapy regimen is required, providing $>95 \%$ of remissions in stage I patients and $75-80 \%$ in stage III and IV patients (58).

\section{A model of care for AYA with gynecological tumors}

The Figure 1 shows a feasible model of multidisciplinary and personalized care for adolescent and AYA with gynecological tumors.

Like all their peers, AYA with gynecological tumors may experience a greater delay between the symptoms onset and the diagnosis than children and adults, with subsequent negative clinical outcomes (59-61). The factors that may prolong diagnostic time are variable, mainly related to their progressive request of autonomy from parental supervision, to the embarrassment or rejection of impairment in body images, but also because physicians who are the initial contact with them less likely believe cancer as a probable diagnosis. Thus, primary health care workers should be educated about the signs and symptoms of gynecological cancers, developing programs to reduce the referral time to oncologic centers (62).

AYA with gynecological tumors were historically committed to pediatric or adult oncologic settings, that are usually unable to provide a personalized model of care for these peculiar groups of patients with age-specific issues (63). However, Marshall et al. showed that the experience of AYA treated in adult settings was usually negative, because of the feeling of isolation from their peers, the lack of empathy from staff, the age-inappropriateness of the adult environment (64). The care of AYA with gynecological malignancies needs a multidisciplinary tumor board of gynecologic oncologist, pediatric oncologists, psychologists, teachers, social workers, oncofertility experts who should work in an informal manner which has been found helpful to AYA (65).

Moreover, the clinical environment should be optimized, providing dedicated spaces with colorful and friendly style, relaxation areas, music facilities, games consoles, that support socialization with their cancer peers (66).

Another challenging issue among that may show AYA patients with gynecological malignancies is the poor adherence to appointments and treatment (67). Several strategies may be adopted by health care providers to 
enhance adherence to treatment. In fact, clinicians may modify communication style, encouraging a non-judgmental approach and increasing availability of psychosocial support; besides they may produce flexibility in treatment plans, simplifying the dosing schedule and adjusting treatments to minimize interference of the regimen with the AYA's lifestyle (68). They may reinforce the adherence behaviors with explicit rewards, which should be individualized on the basis of what is important for motivating each patient (69-71).

Concerning the treatment, clinicians should consider that during the pubertal process several changes may modify the pharmacokinetics and the pharmacodynamics of drugs. Hormonal environment, change in body composition, the increased size of liver and kidneys and their improved capacity to metabolized drugs and secretion, the potential use of tobacco, alcohol or illicit drugs, can influence the absorption, distribution, metabolism and elimination of therapeutical drugs $(11,72)$. The time of onset of these changes varies between each patient. Female AYA experience a sex-specific change in body composition, with earlier increases of GH secretion and greater growth in fat mass than males (73). Furthermore, clinicians have to consider possible interaction between multiple drugs and oral contraceptives containing 17alpha-ethinylestradiol which is a substrate of CYP3A4 and an inhibitor of several human drug-metabolizing cytochromes P450 (74,75). Therefore, in order to resolve the uncertainty regarding what dose intensity of treatment AYA patients with gynecological tumors should receive, it's crucial to improve their enrollment in clinical trials for cancer, which should be considered the gold standard of care. Still, data from literature reported poor inclusion rates of AYA in cancer clinical trials, with an inferior treatment, reduced outcomes and the subsequent lack of improvement in survival $(76,77)$. Involvement rates for AYA varies from 5-34\% compared to over $90 \%$ in children $(3,78)$. Shaw et al. found that AYA enrollment is lower when they are referred in adult medical oncology settings, as opposed to a pediatric oncology setting. Moreover, also the institution type seems to negatively influence their recruitment, which results lower for those treated in community oncology hospitals and not in pediatric tertiary institutions (79).

Thus, an increased collaboration between pediatric and adult gynecological oncologists in a national cooperative group with shared resources and tumor boards should be hoped, in order to remove age limitations to clinical trial recruitment $(5,80)$.

Fern et al. proposed a conceptual strategy for improving participation of AYA to clinical trials, based on five key areas (the five "A" framework): appropriateness of age inclusion criteria, availability of new agents for clinical trials, accessibility to clinical trials in all treatment centers, awareness of AYA cancers by drug developers and acceptability of trial design and research questions both to patients and health-care professionals (81). Recently, the Cancer Drug Development Forum, the European Society for Pediatric Oncology (SIOPE) and the Innovative Therapies for Children with Cancer (ITCC) found "ACCELERATE", a multi-stakeholder platform for including adolescents above 12 years old in adult phase early-phase clinical drug trials, even in phase I human trials where there is a scientific rationale and a potential therapeutic benefit, in order to enhance opportunities for AYA to be included in earlyphase trials (82).

Clinical trials participation requires clinician awareness but also the acceptance by the patients and their family. Therefore, a dedicated oncology plan for AYA with gynecological cancer through the collaboration between pediatric and gynecologic oncologists should be achieved, creating joint clinical and educational meetings, sharing the resource, stimulating research in AYA gynecologic oncology, supporting educational programs about the distinctive needs of AYA.

\section{Specific gynecological concerns}

Despite the effort to optimize cancer treatment to guarantee excellent outcomes, clinicians should have the concern about the enhanced risk of adverse reproductive effects of radiotherapy, chemotherapy and surgery adopted for gynecologic cancer treatment (83).

When possible, fertility-sparing surgery should be chosen, in order to limit infertility, sexual dysfunctions, pelvic pain, adhesion or fistula subsequent to major pelvic surgery (84-86).

Moreover, pelvic radiotherapy may cause ovarian insufficiency (for the loss of ovarian follicle or their impaired maturation) with subsequent infertility, amenorrhea and decreased libido, when there are applied more than 5 Gy in single dose, whereas for fractionated radiation the sterilizing dose decreases with the age, switching from 20.3 Gy at birth to 14.3 Gy at 30 years $(87,88)$.

Doses of 14-30 Gy of pelvic irradiation may predispose the uterus to myometrial fibrosis, and vascular and endometrial injury, with subsequent future pregnancy complications, such as preterm birth, low birth weight, 
malposition of the fetus, spontaneous abortion, placental abnormalities. Doses above of 90-100 Gy may damage the vaginal epithelium and cervix, with fibrosis, fistula, dyspareunia $(89,90)$.

Concerning chemotherapy, the more commonly employed drugs in gynecologic cancer are alkylating agents (cyclophosphamide and ifosfamide), which have as target follicles at every stage of the cycle, causing atresia and high risk (more than $70 \%$ ) of permanent amenorrhoea. About other agents, platinum compounds, temozolomide, dacarbazine, lomustine, procarbazine, melphalan, busulphan, thiotepa are potentially associated to the risk of ovarian dysfunction, which is enhanced and more probably permanent in the case of post-pubertal exposures (91).

The multidisciplinary team of care of AYA with gynecologic tumors should include also oncofertility experts, endocrinologist, perinatologist, that may ensure to the patients an exact management of gynecologic issues during and at the end of the treatment, such as primary ovarian insufficiency (POI), menstrual suppression and contraception, fertility preservation and future pregnancy issues, late psychological and psychosocial effects (92).

\section{POI}

The loss of ovarian function subsequent to gonadal toxic therapy puts women not only at high risk of infertility, but it is also associated with multiple health risks and precocious menopausal symptoms, including dry eye syndrome, osteopenia/osteoporosis and increased risk of fractures, early cardiovascular disease, depression, anxiety, early decline in cognition (93). Thus, most of AYA with gynecological cancer should undergo to long-term (until the normal age of menopause) hormonal replacement therapy, to restore the premenopausal level of ovarian sex steroids, improving their QoL $(94,95)$.

\section{Menstrual suppression and contraception}

Female AYA treated with chemotherapy have a higher risk of heavy menstrual bleeding, which should be avoided especially during the phase of anemia subsequent to the myelosuppression.

Furthermore, sexually active women should be educated about the opportunity of contraception, because of the increased risk of congenital fetal malformation subsequent to chemo or radiotherapy during pregnancy (96).

Options for menstrual suppression may include oral contraceptives or gonadotropin-releasing hormone agonists (GnRHa), such as leuprolide acetate, which is widely adopted by the pediatric oncologist for inducing therapeutic amenorrhea. Its administration should start 2-4 weeks before the beginning chemotherapy and prolonged until the end of the treatment (97).

The choosing of the type of menstrual suppression should be tailored to the patient, her cancer diagnosis, treatment plan, her desires for contraception and fertility (98).

GnRHa reduces the gonadotropin levels, placing the ovarian in an artificial prepubertal state. Furthermore, several studies have demonstrated its protective role against the development of POF after gonad-toxic chemotherapy, increasing the probability of spontaneous pregnancy in the short term (99-101).

\section{Fertility preservation and future pregnancy outcomes}

As their pathological state potentially limits the chances of getting pregnant, fertility preservation is a crucial issue for AYA with gynecological malignancy. A personalized oncofertility counseling should be provided before starting treatment, in order to guarantee a fertility preservation plan tailored on patient's age, characteristics and ethical issues (desire to use a male partner or banked donor sperm), stage of disease, histology, type of treatment $(102,103)$. Anti-mullerian hormone (AMH) seems a useful marker for assessing ovarian reserve, thus it may be used as screening tool for choosing which patients are eligible for the techniques of fertility preservation (104).

Fertility-sparing surgeries should be adopted in selected candidates. For microinvasive stage IA1 cervical cancer a fertility-sparing conization should be performed, which consist in the removal of the ectocervix and the endocervical canals (105). In the patients with stage IA2-IB1 (with lymphovascular space invasion) a fertility preserving radical trachelectomy (FPRT) is a valid option that should be considered, removing the cervix with the preservation of the uterus (106).

Ovarian cancers are usually diagnosed in advanced stages, consequently conservative surgery, with the preservation of uterus and contralateral ovary) should be adopted in malignant GCTs and stage 1 unilateral, well-differentiated and encapsulated epithelial lesions, without adhesions or ascites (107).

Endometrial cancer mostly occurs in the postmenopausal age and standard of care is total hysterectomy and bilateral salpingo-oophorectomy. Only complex atypical hyperplasia 
and grade 1 adenocarcinoma should be treated with medical progestin therapy. Patients with low-risk endometrial carcinoma should undergo to ovarian conservation at the time of hysterectomy $(108,109)$.

Chemotherapeutic agents may have changing degree of gonadotoxicities, which depends on mechanism of action, but also on dose and time of treatment. Alkylating agents (ifosfamide, cyclophosphamide), busulfan and melphalan are associated to a high risk of gonadotoxicity (110). Platinum agents (cisplatin and carboplatin), taxanes, anthracyclines are correlated with a moderate risk of gonadotoxicity (111). Patients treated with antimetabolites (Gemcitabine, 5 -fluoruracile), vincristine, methotrexate have a low risk of gonadotoxicities (<20\%). Moreover, chemotherapy toxicity is age-dependent and it may produce a higher gonadotoxicity in the older patients with a fewer ovarian reserve (112).

Radiation may accelerate oocyte atresia, causing a premature ovarian failure (POF) (113). Furthermore, uterine exposure to radiation is associated to several adverse pregnancy-related complications (114), principally due to pelvic radiation, including mostly premature birth and low birth weight fetal malposition, but also abnormal placentation, hypertensive disorders, uterine rupture. Conversely, the risk of malformations, genetic disorders and cancer seems not to be greater than in their siblings' control $(115,116)$. The risk of developing cancer in offspring born raises in the presence of a germline cancer mutation in the cancer survivors (117).

Patients treated with pelvic radiation should undergo to ovarian transposition, also known as oophoropexy, in order to remove the gonads from the radiation field, putting them into the into the paracolic gutters in the iliac fossae. This technique has a success rate of $70-100 \%$, with possible side effects, including chronic pelvic pain, ovarian cyst, Fallopian tube infarction $(118,119)$.

Cryopreservation techniques should be proposed to AYA with gynecologic cancer before the beginning of therapy. Considering the high ovarian reserve in women younger than 40 years, these patients should undergo to cryopreservation of cortical ovarian tissue (rich of primordial follicles with oocytes), which is obtained with laparoscopic approach, cryopreserved for later reimplantation or in vitro maturation of oocytes), without the need of partner or ovarian stimulation $(120,121)$.

Cryopreservation of oocytes or embryos also may be purposed, but either requires a stimulation with gonadotropin for oocyte retrieval. Oocyte-cryopreservation showed lower pregnancy rates compared to embryocryopreservation $(5-12 \%$ versus $30-40 \%)$, but it should choose by patients without male partners or who don't want a donor sperm (122).

As mentioned above, GnHRa has to be considered as a chance to preserve ovarian function and fertility after cytotoxic treatment (99-101).

\section{Late psychological and psychosocial effects of gynecological cancer}

AYA with gynecological cancer may experience for a long time, even after the end of therapy, several psychologic and psychosocial disorders, including fatigue, sleep disorders, body image disorders, anxiety, depression, cognitive and functional limitations, sexual dysfunction, infertility, limited emotional relationship, work or school issues $(123,124)$. Consequently, it's crucial for to quickly identify those patients who are at greater risk of developing sexual, psychological and psychosocial problems, with an expert and prompt support, in order to improve their QoL $(125,126)$.

\section{Conclusions}

AYA with gynecologic tumors are a distinctive group of patients with specific issues, that require personalized and management. Their cancer board should be multidisciplinary, involving pediatric and gynecological oncologists, in order to provide them with the better standard of care in a suitable environment, assuring the enrollment into clinical trials.

Moreover, other professional figures, including endocrinologists, oncofertility experts, psychologists, teachers, social workers should help the oncologists to manage their gynecologic specific issues about ovarian failure, contraception, fertility, late psychosocial effects.

Although the great residual and unresolved questions and concerns about this topic, with our paper we hope to have stimulated and encouraged oncologists to attempt evermore the best management for their AYA patients with gynecologic malignancies.

\section{Acknowledgments}

Funding: This work was supported by Fondazione per l'Oncologia Pediatrica. 


\section{Footnote}

Conflicts of Interest: The authors have no conflicts of interest to declare.

Ethical Statement: The authors are accountable for all aspects of the work in ensuring that questions related to the accuracy or integrity of any part of the work are appropriately investigated and resolved.

Open Access Statement: This is an Open Access article distributed in accordance with the Creative Commons Attribution-NonCommercial-NoDerivs 4.0 International License (CC BY-NC-ND 4.0), which permits the noncommercial replication and distribution of the article with the strict proviso that no changes or edits are made and the original work is properly cited (including links to both the formal publication through the relevant DOI and the license). See: https://creativecommons.org/licenses/by-nc-nd/4.0/.

\section{References}

1. Adolescent and Young Adult Oncology Progress Review Group: Closing the Gap: Research and Care Imperatives for Adolescents and Young Adults with Cancer. Bethesda, MD, Department of Health and Human Services, National Institutes of Health, National Cancer Institute, and the LiveStrong Young Adult Alliance, 2006.

2. Desandes E, Stark DP. Epidemiology of Adolescents and Young Adults with Cancer in Europe. Prog Tumor Res 2016;43:1-15.

3. Tai E, Buchanan N, Eliman D, et al. Understanding and addressing the lack of clinical trial enrollment among adolescents with cancer. Pediatrics 2014;133:S98-103.

4. World Health Organization - Health Topics. Adolescent Health. n.d. Available online: http://www.who.int/topics/ adolescent_health/en/ (accessed January 24, 2018).

5. Tai E, Buchanan N, Westervelt L, et al. Treatment setting, clinical trial enrollment, and subsequent outcomes among adolescents with cancer: a literature review. Pediatrics 2014; 133 Suppl 3:S91-7.

6. Bleyer A, Barr R, Hayes-Lattin B, et al. The distinctive biology of cancer in adolescents and young adults. Nat Rev Cancer 2008;8:288-98.

7. Bleyer A. Older adolescents with cancer in North America deficits in outcome and research. Pediatr Clin North Am 2002;49:1027-42.

8. Close AG, Dreyzin A, Miller KD, et al. Adolescent and young adult oncology-past, present, and future. CA Cancer J Clin 2019. [Epub ahead of print].

9. Stepanian M, Cohn DE. Gynecologic malignancies in adolescents. Adolesc Med Clin 2004;15:549-68.

10. Winer I, Patel D, Dalton V, et al. Involvement and comfort of gynecologic oncologists in the treatment of pediatric, adolescent, and young adult patients with gynecologic malignancies. Int J Gynaecol Obstet 2017;138:177-82.

11. Veal GJ, Hartford CM, Stewart CF. Clinical pharmacology in the adolescent oncology patient. J Clin Oncol 2010;28:4790-9.

12. Richter D, Koehler M, Friedrich M, et al. Psychosocial interventions for adolescents and young adult cancer patients: A systematic review and meta-analysis. Crit Rev Oncol Hematol 2015;95:370-86.

13. Goodman A. Abnormal genital tract bleeding. Clin Cornerstone 2000;3:25-35.

14. Schultz KA, Sencer SF, Messinger Y, et al. Pediatric ovarian tumors: a review of 67 cases. Pediatr Blood Cancer 2005;44:167-73.

15. Koulouris CR, Penson RT. Ovarian stromal and germ cell tumors. Semin Oncol 2009;36:126-36.

16. Shanbhogue AK, Shanbhogue DK, Prasad SR, et al. Clinical syndromes associated with ovarian neoplasms: a comprehensive review. RadioGraphics 2010;30:903-19.

17. Young RH, Dickersin GR, Scully RE. Juvenile granulosa cell tumor of the ovary: a clinicopathological analysis of 125 cases. Am J Surg Pathol 1984;8:575-96.

18. Scully RE. Gonadoblastoma: a review of 74 cases. Cancer 1970;25:1340-56.

19. De Backer A, Madern GC, Oosterhuis JW, et al. Ovarian germ cell tumors in children: a clinical study of 66 patients. Pediatr Blood Cancer 2006;46:459-64.

20. Wakeham K, Kavanagh K, Cuschieri K, et al. HPV status and favourable outcome in vulvar squamous cancer. Int J Cancer 2017;140:1134-46.

21. Ambros RA, Kurman RJ. Tumors of the vulva. In: Carpenter SE, Rock JA, editors. Pediatric and adolescent gynecology. 2nd ed. Philadelphia: Lippincott Williams \& Wilkins, 2000:393-402.

22. La Vecchia C, Draper GJ, Franceschi S. Childhood nonovarian female genital tract cancers in Britain, 1962-1978. Descriptive epidemiology and long-term survival. Cancer 1984;54:188-92.

23. Flanagan CW, Parker JR, Mannel RS, et al. Primary endodermal sinus tumor of the vulva: a case report and review of the literature. Gynecol Oncol 1997;66:515-8.

24. Choi CM, Majmudar B, Horowitz IR. Malignant 
neoplasms of the vagina and cervix in the neonate, child, and adolescent. In: Carpenter SE, Rock JA. editors.

Pediatric and adolescent gynecology. 2nd ed. Philadelphia: Lippincott Williams \& Wilkins, 2000:403-23.

25. Huo D, Anderson D, Palmer JR, et al. Incidence rates and risks of diethylstilbestrol-related clear-cell adenocarcinoma of the vagina and cervix: Update after40-year follow-up. Gynecol Oncol 2017;146:566-71.

26. Behtash N, Mousavi A, Tehranian A, et al. Embryonal rhabdomyosarcoma of the uterine cervix: case report and review of the literature. Gynecol Oncol 2003;91:452-5.

27. Narin MA, Karalok A, Basaran D, et al. Embryonal Rhabdomyosarcoma of the Cervix in Young Women. J Adolesc Young Adult Oncol 2016;5:261-6.

28. Sobiczewski P, Dańska-Bidzińska A, Miedzinska M, et al. Polypectomy followed by adjuvant chemotherapy in a patient with sarcoma botryoides of the uterine cervix-case report and review of the literature. Ginekol Pol 2011;82:857-61.

29. Arndt CAS, Donaldson SS, Anderson JR, at al. What Constitutes Optimal Therapy for Patients with Rhabdomyosarcoma of the Female Genital Tract? Cancer 2001;91:2454-68.

30. Bhatt MD, Braga LH, Stein N, et al. Vaginal Yolk Sac Tumor in an Infant: A Case Report and Literature Review of the Last 30 Years. J Pediatr Hematol Oncol 2015;37:e336-40.

31. Liebhart M. Histopathological diagnosis of vaginal endodermal sinus tumors in infants. Int J Gynecol Pathol 1986;5:217-22.

32. Rajagopal R, Ariffin H, Krishnan S, et al. Pediatric Vaginal Yolk Sac Tumor: Reappraisal of Treatment Strategy in a Rare Tumor at a Unique Location. J Pediatr Hematol Oncol 2015;37:391-5.

33. Baykara M, Benekli M, Erdem O, et al. Clear Cell Adenocarcinoma of the Uterine Cervix: A Case Report and Review of the Literature. J Pediatr Hematol Oncol 2014;36:e131-3.

34. McNall RY, Nowicki PD, Miller B, et al. Adenocarcinoma of the cervix and vagina in pediatric patients. Pediatr Blood Cancer 2004;43:289-94.

35. Quinn MA, Kneale BJ, Fortune DW. Endometrial carcinoma in premenopausal women: a clinicopathological study. Gynecol Oncol 1985;20:298-306.

36. Smyczek-Gargya B, Geppert M. Endometrial cancer associated with polycystic ovaries in young women. Pathol Res Pract 1992;188:946-8.

37. Koivisto-Korander R, Butzow R Koivisto AM, et al.
Clinical outcome and prognostic factors in 100 cases of uterine sarcoma: Experience in Helsinki University Central Hospital 1990-2001 Gynecologic Oncology. 2008;111:74-81.

38. Kahanpää KV, Wahlstrom T, Grohn P, et al. Sarcomas of the uterus: a clinicopathologic study of 119 patients. Obstet Gynecol 1986;67:417-24.

39. Eskander R, Berman M, Keder L. Practice Bulletin No. 174: Evaluation and Management of Adnexal Masses. American College of Obstetricians and Gynecologists' Committee on Practice Bulletins-Gynecology. Obstet Gynecol 2016;128:e210-26.

40. Al Jama FE, Al Ghamdi AA, Gasim T, et al. Ovarian tumors in children and adolescents-a clinical study of 52 patients in a university hospital. J Pediatr Adolesc Gynecol 2011;24:25.

41. Cribb B, Vishwanath N, Upadhyay V. Paediatric ovarian lesions--the experience at Starship Children's Hospital, New Zealand. N Z Med J 2014;127:41-51.

42. Fleming NA, de Nanassy J, Lawrence S, et al. Juvenile Granulosa and Theca Cell Tumor of the Ovary as a Rare Cause of Precocious Puberty: Case Report and Review of Literature. J Pediatr Adolesc Gynecol 2010;23:e127-31.

43. Schneider DT, Orbach D, Cecchetto G, et al. Ovarian Sertoli Leydig cell tumours in children and adolescents: an analysis of the European Cooperative Study Group on Pediatric Rare Tumors (EXPeRT). Eur J Cancer 2015;51:543-50.

44. Schneider DT, Calaminus G, Harms D, et al. Ovarian sex cord-stromal tumors in children and adolescents. J Reprod Med 2005;50:439-46.

45. Schumer ST, Cannistra SA. Granulosa cell tumor of the ovary. J Clin Oncol 2003;21:1180-9.

46. Oltmann SC, Fischer A, Barber R et al. Pediatric ovarian malignancy presenting as ovarian torsion: incidence and relevance. J Pediatr Surg 2010;45:135-9.

47. Outwater EK, Wagner BJ, Mannion C, et al. Sex cord-stromal and steroid cell tumors of the ovary. RadioGraphics 1998;18:1523-46.

48. Schneider DT, Jänig U, Calaminus G, et al. Ovarian sex cord-stromal tumors: a clini-copathological study of 72 cases from the Kiel Pediatric Tumor Registry. Virchows Arch 2003;443:549-60.

49. Roth LM. Recent advances in the pathology and classification of ovarian sex cord-stromal tumors. Int J Gynecol Pathol 2006;25:199-215.

50. Ulbright TM. Germ cell tumors of the gonads: a selective review emphasizing problems in differential diagnosis, 


\section{Page 10 of 12}

newly appreciated, and controversial issues. Mod Pathol 2005;18:S61-79.

51. Cecchetto G. Gonadal germ cell tumors in children and adolescents. J Indian Assoc Pediatr Surg 2014;19:189-94.

52. Sheiko MC, Hart WR. Ovarian germinoma (dysgerminoma) with elevated serum lactic dehydrogenase: case report and review of literature. Cancer 1982;49:994-8.

53. Laufer MR, Goldstein DP. Benign and malignant ovarian masses. In: Emans SJH, Laufer MR, Goldstein DP. editors. Pediatric and adolescent gynecology. 5th ed. Philadelphia: Lippincott Williams \& Wilkins, 2005:685.

54. Harada M, Osuga Y, Fujimoto A, et al. Predictive factors for recurrence of ovarian mature cystic teratomas after surgical excision. Eur J Obstet Gynecol Reprod Biol 2013;171:325-8.

55. Gershenson DM, del Junco G, Silva EG, et al. Immature teratoma of the ovary. Obstet Gynecol 1986;68:624-9.

56. Yamaoka T, Togashi K, Koyama T, et al. Immature teratoma of the ovary: correlation of MR imaging and pathologic findings. Eur Radiol 2003;13:313-9.

57. Kurman RJ, Norris HJ. Embryonal carcinoma of the ovary: a clinicopathologic entity distinct from endodermal sinus tumor resembling embryonal carcinoma of the adult testis. Cancer 1976;38:2420-33.

58. Agarwala S, Mitra A, Bansal D, et al. Management of Pediatric Malignant Germ Cell Tumors: ICMR Consensus Document. Indian J Pediatr 2017;84:465-72.

59. Brasme JF, Morfouace M, Grill J, et al. Delays in diagnosis of paediatric cancers: a systematic review and comparison with expert testimony in lawsuits. Lancet Oncol 2012;13:e445-59.

60. Ferrari A, Lo Vullo S, Giardiello D, et al. The sooner the better? How symptom interval correlates with outcome in children and adolescents with solid tumors: regression tree analysis of the findings of a prospective study. Pediatr Blood Cancer 2016;63:479-85.

61. Jin SL, Hahn SM, Kim HS, et al. Symptom interval and patient delay affect survival outcomes in adolescent cancer patients. Yonsei Med J 2016;57:572-9.

62. Herbert A, Lyratzopoulos G, Whelan J et al. Diagnostic timeliness in adolescents and young adults with cancer: a cross-sectional analysis of the BRIGHTLIGHT cohort. Lancet Child Adolesc Health 2018;2:180-90.

63. Jones LJ, Pini SA, Morgan SJ, et al. How Do Teenagers and Young Adults with Cancer Experience Their Care? A European Survey. J Adolesc Young Adult Oncol 2017;6:102-10.

64. Marshall S, Grinyer A, Limmer M. The Experience of

\section{Triarico et al. Fertility issues as a model of personalized care}

Adolescents and Young Adults Treated for Cancer in an Adult Setting: A Review of the Literature. J Adolesc Young Adult Oncol 2018;7:283-91.

65. Phillips CR, Davis LL. Psychosocial Interventions for Adolescents and Young Adults with Cancer. Semin Oncol Nurs 2015;31:242-50.

66. Bernig T, Jahn F, Witkowsky S, et al. Treatment of adolescents and young adults (AYA) with cancer in a multidisciplinary setting: on the way to a highly specialized AYA unit. Klin Padiatr 2013;225:335-8.

67. Kondryn HJ, Edmondson CL, Hill J, et al. Treatment non-adherence in teenage and young adult patients with cancer. Lancet Oncol 2011;12:100-8.

68. Taddeo D, Egedy M, Frappier JY. Adherence to treatment in adolescents. Paediatr Child Health 2008;13:19-24.

69. Butow P, Palmer S, Pai A, et al. Review of adherence related issues in adolescents and young adults with cancer. J Clin Oncol 2010;28:4800-9.

70. McNeil R, Egsdal M, Drew S, et al. The changing nature of social support for adolescents and young adults with cancer. Eur J Oncol Nurs 2019;43:101667.

71. Osborn M, Johnson R, Thompson K, et al. Models of care for adolescent and young adult cancer programs. Pediatr Blood Cancer 2019;66:e27991.

72. Bukowinski AJ, Burns KC, Parsons K et al. Toxicity of Cancer Therapy in Adolescents and Young Adults (AYAs). Semin Oncol Nurs 2015;31:216-26.

73. Loomba-Albrecht LA, Styne DM.Effect of puberty on body composition. Curr Opin Endocrinol Diabetes Obes 2009; 16:10-5.

74. Zhang H, Cui D, Wang B, et al. Pharmacokinetic drug interactions involving 17alpha-ethinylestradiol: a new look at an old drug. Clin Pharmacokinet 2007;46:133-57.

75. Chang SY, Chen C, Yang Z, et al. Further assessment of 17alpha-ethinyl estradiol as an inhibitor of different human cytochrome P450 forms in vitro. Drug Metab Dispos 2009;37:1667-75.

76. Fern LA, Whelan JS. Recruitment of adolescents and young adults to cancer clinical trials-international comparisons, barriers, and implications. Semin Oncol 2010;37:e1-8.

77. Ferrari A, Montello M, Budd T, et al. The challenges of clinical trials for adolescents and young adults with cancer. Pediatr Blood Cancer 2008;50:1101-4.

78. Bleyer WA, Tejeda H, Murphy SB, et al. National cancer clinical trials: Children have equal access; Adolescents do not. J Adolesc Health 1997;21:366-73.

79. Shaw PH, Hayes-Lattin B, Johnson R, et al. Improving 
enrollment in clinical trials for adolescents with cancer. Pediatrics 2014;133:S109-13.

80. Ramphal R, Meyer R, Schacter B, et al. Active therapy and models of care for adolescents and young adults with cancer. Cancer 2011;117:2316-22.

81. Fern LA, Lewandowski JA, Coxon KM, et al. National Cancer Research Institute Teenage and Young Adult Clinical Studies Group, UK. Available, accessible, aware, appropriate, and acceptable: a strategy to improve participation of teenagers and young adults in cancer trials. Lancet Oncol 2014; 15:e341-50.

82. Gaspar N, Marshall LV, Binner D, et al. Joint adolescentadult early phase clinical trials to improve access to new drugs for adolescents with cancer: proposals from the multi-stakeholder platform-ACCELERATE. Ann Oncol 2018;29:766-71.

83. George SA, Williamson Lewis R, McKenzie L, et al. Assessment of ovarian function in adolescents and young adults after childhood cancer treatment-How accurate are young adult/parent proxy-reported outcomes? Pediatr Blood Cancer 2019;66:e27981.

84. Johansen G, Dahm-Kähler P, Staf C, et al. Fertility-sparing surgery for treatment of non-epithelial ovarian cancer: Oncological and reproductive outcomes in a prospective nationwide population-based cohort study. Gynecol Oncol 2019;155:287-93.

85. Zapardiel I, Diestro MD, Aletti G. Conservative treatment of early stage ovarian cancer: oncological and fertility outcomes. Eur J Surg Oncol 2014;40:387-93.

86. Bentivegna E, Maulard A, Miailhe G, et al. Gynaecologic cancer surgery and preservation of fertility. J Visc Surg 2018;155:S23-9.

87. Wallace WH, Thomson AB, Saran F, et al. Predicting age of ovarian failure after radiation to a field that includes the ovaries. Int J Radiat Oncol Biol Phys 2005;62:738-44.

88. Schuck A, Hamelmann V, Brämswig JH, et al. Ovarian function following pelvic irradiation in prepubertal and pubertal girls and young adult women. Strahlenther Onkol 2005;181:534-9.

89. Critchley HO, Bath LE, Wallace WH. Radiation damage to the uterus - review of the effects of treatment of childhood cancer. Hum Fertil (Camb) 2002;5:61-6.

90. Sudour H, Chastagner P, Claude L, et al. Fertility and pregnancy outcome after abdominal irradiation that included or excluded the pelvis in childhood tumor survivors. Int J Radiat Oncol Biol Phys 2010;76:867-73.

91. Overbeek A, van den Berg MH, van Leeuwen FE, et al. Chemotherapy-related late adverse effects on ovarian function in female survivors of childhood and young adult cancer: A systematic review. Cancer Treat Rev 2017;53:10-24.

92. Committee opinion no. 607: Gynecologic concerns in children and adolescents with cancer. Obstet Gynecol 2014;124:403-8.

93. Torrealday S, Kodaman P, Pal L. Premature Ovarian Insufficiency - an update on recent advances in understanding and management. F1000Res 2017;6:2069.

94. Fenton AJ. Premature ovarian insufficiency: Pathogenesis and management. J Midlife Health 2015;6:147-53.

95. Sullivan SD, Sarrel PM, Nelson LM. Hormone replacement therapy in young women with primary ovarian insufficiency and early menopause. Fertil Steril 2016;106:1588-99.

96. Vandenbroucke T, Verheecke M, Fumagalli M, et al. Effects of cancer treatment during pregnancy on fetal and child development. Lancet Child Adolesc Health 2017;1:302-10.

97. Adegite EA, Goyal RK, Murray PJ, et al. The management of menstrual suppression and uterine bleeding: a survey of current practices in the Pediatric Blood and Marrow Transplant Consortium. Pediatr Blood Cancer 2012;59:553-7.

98. Committee opinion no. 606: Options for prevention and management of heavy menstrual bleeding in adolescent patients undergoing cancer treatment. Obstet Gynecol 2014;124:397-402.

99. Munhoz RR, Pereira AA, Sasse AD et al. GonadotropinReleasing Hormone Agonists for Ovarian Function Preservation in Premenopausal Women Undergoing Chemotherapy for Early-Stage Breast Cancer: A Systematic Review and Meta-analysis. JAMA Oncol 2016;2:65-73.

100.Senra JC, Roque M, Talim MCT et al. Gonadotropinreleasing hormone agonists for ovarian protection during cancer chemotherapy: systematic review and meta-analysis. Ultrasound Obstet Gynecol 2018;51:77-86.

101. Hickman LC, Llarena NC, Valentine LN, et al. Preservation of gonadal function in women undergoing chemotherapy: a systematic review and meta-analysis of the potential role for gonadotropin-releasing hormone agonists. J Assist Reprod Genet 2018;35:571-81.

102. Liu Y, Zhang WY. Recent advances for improving fertility in gynaecological cancer patients. Eur Rev Med Pharmacol Sci 2015;19:3224-8.

103. De Felice F, Marchetti C, Di Pinto A, et al. Fertility preservation in gynaecologic cancers. 
Ecancermedicalscience 2018;12:798.

104. Broer SL, Broekmans FJ, Laven JS, et al. Anti-Müllerian hormone: ovarian reserve testing and its potential clinical implications. Hum Reprod Update 2014;20:688-701.

105. Bogani G, Chiappa V, Vinti D, et al. Long-term results of fertility-sparing treatment for early-stage cervical cancer. Gynecol Oncol 2019;154:89-94.

106. Costales A, Michener C, Escobar-Rodriguez PF. Radical Trachelectomy for Early Stage Cervical Cancer. Curr Treat Options Oncol 2018;19:75.

107. Bentivegna E, Gouy S, Maulard A, et al. Fertility-sparing surgery in epithelial ovarian cancer: a systematic review of oncological issues. Ann Oncol 2016;27:1994-2004.

108. Carneiro MM, Lamaita RM, Ferreira MC. Fertilitypreservation in endometrial cancer: is it safe? Review of the literature. JBRA Assist Reprod 2016;20:232-9.

109. Vitale SG, Rossetti D, Tropea A, et al. Fertility sparing surgery for stage IA type I and G2 endometrial cancer in reproductive-aged patients: evidence-based approach and future perspectives. Updates Surg 2017;69:29-34.

110. Sonigo C, Beau I, Binart N, et al. The Impact of Chemotherapy on the Ovaries: Molecular Aspects and the Prevention of Ovarian Damage. Int J Mol Sci 2019. doi: 10.3390/ijms20215342.

111. Bedoschi G, Navarro PA, Oktay K. Chemotherapyinduced damage to ovary: mechanisms and clinical impact. Future Oncol 2016;12:2333-44.

112. McKenzie ND, Kennard JA, Ahmad S. Fertility preserving options for gynecologic malignancies: A review of current understanding and future directions. Crit Rev Oncol Hematol 2018;132:116-24.

113. Signorello LB, Cohen SS, Bosetti C, et al. Female survivors of childhood cancer: preterm birth and low birth weight among their children. J Natl Cancer Inst 2006;98:1453-61.

114. Mueller BA, Chow EJ, Kamineni A, et al. Pregnancy outcomes in female childhood and adolescent cancer survivors: a linked cancer-birth registry analysis. Arch Pediatr Adolesc Med 2009;163:879-86.

Cite this article as: Triarico S, Capozza MA, Mastrangelo S, Attinà G, Maurizi P, Ruggiero A. Gynecological cancer among adolescents and young adults (AYA). Ann Transl Med 2020;8(6):397. doi: 10.21037/atm.2020.02.41
115.Dursun P, Ayhan A, Yanik FB, et al. Ovarian transposition for the preservation of ovarian function in young patients with cervical carcinoma. Eur J Gynaecol Oncol 2009;30:13-5.

116. Swift BE, Leung E, Vicus D et al. Laparoscopic ovarian transposition prior to pelvic radiation for gynecologic cancer. Gynecol Oncol Rep 2018;24:78-82.

117. Practice Committee of American Society for Reproductive Medicine. Ovarian tissue cryopreservation: a committee opinion Fertil Steril 2014; 101:1237-43.

118. Donnez J, Martinez-Madrid B, Jadoul P, et al. Ovarian tissue cryopreservation and transplantation: a review. Hum Reprod Update 2006;12:519-35.

119. Shamonki MI, Oktay K. Oocyte and ovarian tissue cryopreservation: indications, techniques, and applications. Semin Reprod Med 2005;23:266-76.

120.Lie Fong S, van den Heuvel-Eibrink MM, Eijkemans MJ, et al. Pregnancy outcome in female childhood cancer survivors. Hum Reprod 2010;25:1206-12.

121. Green DM, Sklar CA, Boice JD Jr, et al. Ovarian failure and reproductive outcomes after childhood cancer treatment: results from the Childhood Cancer Survivor Study. J Clin Oncol 2009;27:2374-81.

122. Travis LB, Rabkin CS, Brown LM, et al. Cancer survivorship—genetic susceptibility and second primary cancers: research strategies and recommendations. J Natl Cancer Inst 2006;98:15-25.

123. Roland KB, Rodriguez JL, Patterson JR, et al. A literature review of the social and psychological needs of ovarian cancer survivors. Psychooncology 2013;22:2408-18.

124. Vitale SG, La Rosa VL, Rapisarda AM, et al. Comment on "The consequences of gynaecological cancer in patients and their partners from the sexual and psychological perspective". J Cancer Res Ther 2017;13:598-9.

125.Pearman T. Quality of life and psychosocial adjustment in gynecologic cancer survivors. Health Qual Life Outcomes 2003;1:33.

126. Gonçalves V. Long-term quality of life in gynecological cancer survivors. Curr Opin Obstet Gynecol 2010;22:30-5. 